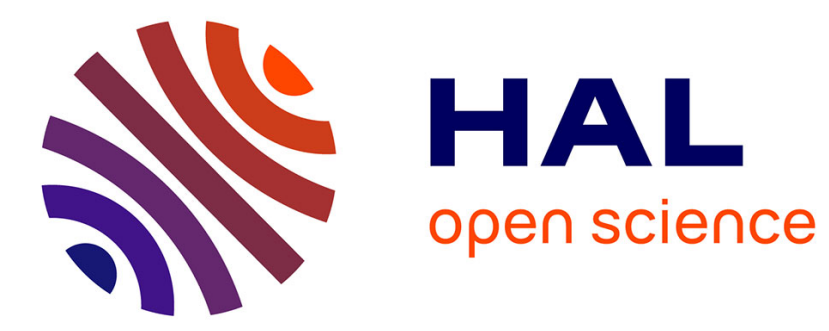

\title{
Novel participatory indicators of sustainability reveal weaknesses of maize cropping in Benin
}

\author{
Rosaine Yegbemey, Jacob Yabi, Codjo Dossa, Siegfried Bauer
}

\section{To cite this version:}

Rosaine Yegbemey, Jacob Yabi, Codjo Dossa, Siegfried Bauer. Novel participatory indicators of sustainability reveal weaknesses of maize cropping in Benin. Agronomy for Sustainable Development, 2014, 34 (4), pp.909-920. 10.1007/s13593-014-0214-9 . hal-01234835

\section{HAL Id: hal-01234835 \\ https://hal.science/hal-01234835}

Submitted on 27 Nov 2015

HAL is a multi-disciplinary open access archive for the deposit and dissemination of scientific research documents, whether they are published or not. The documents may come from teaching and research institutions in France or abroad, or from public or private research centers.
L'archive ouverte pluridisciplinaire HAL, est destinée au dépôt et à la diffusion de documents scientifiques de niveau recherche, publiés ou non, émanant des établissements d'enseignement et de recherche français ou étrangers, des laboratoires publics ou privés. 


\title{
Novel participatory indicators of sustainability reveal weaknesses of maize cropping in Benin
}

\author{
Rosaine Nérice Yegbemey • Jacob Afouda Yabi • \\ Codjo Sylvestre Gerbert Dossa $\cdot$ Siegfried Bauer
}

Accepted: 21 February 2014 / Published online: 28 March 2014

(C) INRA and Springer-Verlag France 2014

\begin{abstract}
Agricultural sustainability is actually measured based on indicators. The choice of indicators is made by scientists alone and is rarely explained. Therefore, the sustainability assessment may be biased because it does not take into account the field knowledge of farmers and agricultural extension officers. Here, we used a novel method using participatory indicators in four steps: (1) group discussions with stakeholders, (2) a survey questionnaire, (3) a household survey, and (4) an estimation of sustainability level. We applied this method to Benin, West Africa, and defined 17 indicators. Some indicators were similar to known indicators, whereas other indicators measured the environmental and social dimensions of sustainability. The method was applied to a case study of maize farming. We found values of 41 for
\end{abstract}

R. N. Yegbemey $(\bowtie) \cdot$ S. Bauer

Institute of Project and Regional Planning,

Faculty of Agricultural Sciences, Nutritional Sciences and

Environmental Management, Justus-Liebig University of Giessen,

Senckenbergstraße 3, 35390 Gießen, Germany

e-mail: yrosaine@hotmail.fr

R. N. Yegbemey

e-mail: rosaine.n.yegbemey@agrar.uni-giessen.de

\section{R. N. Yegbemey · J. A. Yabi}

Laboratoire d'Analyse et de Recherche en Economie et

Developpement (LARED); Departement d'Economie et Sociologie

Rurales, Faculté d'Agronomie, Université de Parakou,

BP 123, Parakou, Republic of Benin

\section{S. G. Dossa}

Plant Breeding, Genetics and Biotechnology,

International Rice Research Institute (IRRI),

DAPO Box 7777, Metro Manila, Philippines

\section{S. G. Dossa}

Institute of Horticultural Production System,

Department of Phytomedicine, Leibniz University of Hannover,

Herrenhäuser Straße 2, 30419 Hannover, Germany economic sustainability, 55 for environmental sustainability, and 40 for social sustainability. This finding evidences some weaknesses of maize farming in northern Benin because the sustainability threshold value is 50 .

Keywords Agricultural sustainability · Farm level · Maize farming · Participatory indicator-based $\cdot$ Sub-Saharan Africa

\section{Introduction}

The role of agriculture is well known in economic growth and rural livelihoods in developing countries, especially in Africa. In these countries, climate change, water scarcity, water pollution, loss of biodiversity, loss of soil fertility, and soil degradation are challenges that adversely affect agriculture, compromising its viability and hindering sustainability. To date, researchers, policy makers, and professionals agree on the importance of sustaining agriculture and the need to develop appropriate methods to measure the sustainability of farming systems (Van Calker et al. 2006; Gafsi et al. 2006) (Fig. 1). Consequently, there is a rich and growing literature on sustainability assessment (e.g., Rigby et al. 2001; Heller and Keoleian 2003; Ness et al. 2007; Sydorovych and Wossink 2008; Gafsi and Favreau 2010; Binder et al. 2010; König 2013).

Nowadays, sustainability assessment is increasingly viewed as an important tool to aid in the shift toward sustainable development but very few examples remain of effective sustainability assessment processes implemented anywhere in the world (Pope et al. 2004). Indeed, though many tools or methods have been developed for agricultural sustainability assessment, their application is often difficult, especially in the context of developing countries, because of the socioeconomic environment (i.e., definition and collection of data often not harmonized, data often irregularly collected, difficulties in 


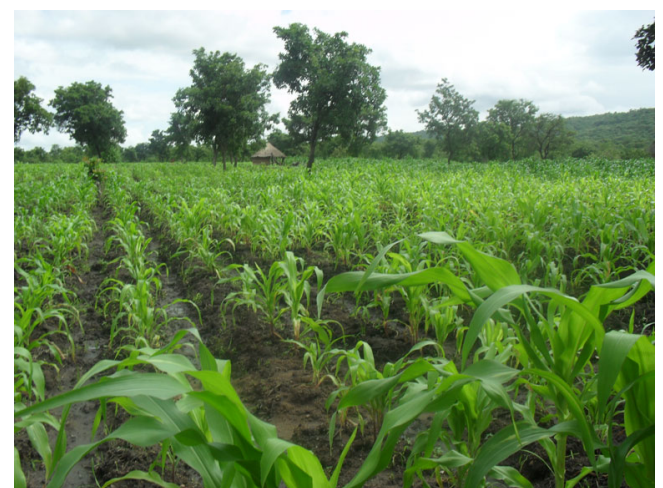

Fig. 1 A sustainable farming system has a good number of benefits such as economic viability, protection of the environment, and the preservation of social coordination

access to data (König 2013), farms with small holdings, lack of data records, etc.).

In the last decade, the scientific community has carried out efforts to build integrated frameworks to support the decision-making process when sustainability concerns are examined (Paracchini et al. 2011). In developing countries, empirical studies on sustainability have been conducted by Reidsma et al. (2011); Purushothaman et al. (2012); König et al. (2013); Liu and Zhang (2013), and Patil et al. (2014) with case studies in China, India, Indonesia, Kenya, and Tunisia. Although these studies have filled, to some extent, the knowledge and research gaps on agricultural sustainability at the farm level in developing countries, they focused specifically on land use problems and followed Sustainability Impact Assessment (SIA) methods, also termed Sustainability Assessment (SA) methods. SIA methods can be viewed as tools or processes based on environmental impact assessment frameworks to assess the impacts or implications of an initiative (e.g., proposed or existing policy, plan, project, piece of legislation, or a current practice or activity) on sustainability (Pope et al. 2004). Whereas most of the SIA methods tend to give more importance to environmental and technical factors, some consider additional indicators specific to agricultural production systems. Twelve selected SIA methods were reviewed in Van der Werf and Petit (2002).

Because observed sustainability is not likely to be determined only by the impacts of a few specific initiatives, most SIA methods might be limited. A direct measurement of the actual sustainability level (we call these Direct Sustainability Measurement (DSM) methods) regardless of specific initiatives can be used as a first step in SIA methods and the measured sustainability level can be used as endogenous data in models to explain observed sustainability under a broader range of initiatives. A few studies (e.g., De Koeijer et al. 2002; Viaux et al. 2008; Gafsi and Favreau 2010) followed this approach. Beyond the impact assessment frameworks, the core idea of DSM methods is to identify and measure directly a set of sustainability indicators. Following Rametsteiner et al. (2011), the role of these indicators is to structure and communicate information about key issues and their trends considered relevant for sustainable development. Despite this importance, the development of sustainability indicators provides a particular challenge to scientists, given the essentially normative dimension of the concept of sustainability (Rametsteiner et al. 2011).

Sub-Saharan Africa, to our knowledge, has no application of DSM methods built on directly measurable indicators. Yet, according to Hayati et al. (2010), indicators to use for agricultural sustainability should be location specific and constructed within the context of contemporary socioeconomic and environmental conditions. This situation suggests a need to define a relevant and suitable sustainability measurement framework applicable in many parts of sub-Saharan Africa while taking into account different socioeconomic environments so as to provide specific and relevant early-warning information. Along this line, this paper describes a novel framework for measuring agricultural sustainability: the Participatory Indicator-Based (PIB) approach. A practical application is provided through the example of maize farming in northern Benin, West Africa.

\section{From sustainability to farm sustainability}

According to Fleming and Vanclay (2010), sustainability is a concept relatively easy to understand but difficult to define in practice. As a matter of fact, there is no standard definition of sustainability and this makes the concept complex and even contested. Nevertheless, defining the concept is a prerequisite for developing an assessment framework (Gafsi and Favreau 2010). At the farm level, Conway (1985) defined sustainability as the ability of a system to maintain productivity in spite of a major disturbance, such as one caused by intensive stress or a large perturbation. Elaborating on Conway's definition, Lynam and Herdt (1989) defined sustainability as the capacity of a system to maintain output at a level approximately equal to or greater than its historical average, with the approximation determined by its historical level of variability.

Beyond the multiple definitions, major and common features are defined for talking about sustainability (Rigby et al. 2001; Pope et al. 2004; Gafsi and Favreau 2010). On the one hand, sustainability is a multidimensional concept and its three dimensions (i.e., economic, 
environmental, and social) at least are broadly acknowledged. On the other hand, there is a clear consensus to move from attempted definitions toward developing and using concrete tools for measuring and promoting actual sustainability achievements (Van Passel et al. 2007). Following the concept definition provided by Conway (1985) and improved by Lynam and Herdt (1989), we define sustainability at the farm level as "the capacity of a farming system to maintain or improve its economic viability over time before major disturbances such as land degradation and climate change occur while respecting the environment and preserving social coordination."

\section{Methods}

3.1 General method for measuring sustainability as derived from the literature

According to Binder et al. (2010), SIA methods can be categorized into three types: (i) top-down farm assessment methods, (ii) top-down regional assessment methods with some stakeholder participation, and (iii) bottom-up integrated participatory or transdisciplinary methods with stakeholder participation throughout the process. The available DSM approaches propose to measure sustainability by means of indicators (indicator-based approaches). Yet, direct indicators for measuring sustainability are largely defined by top-down methods. In DSM methods, the three dimensions of sustainability (i.e., economic, social, and environmental) are broken down into several components. Within each component, one or more indicators are defined and measured (Gafsi and Favreau 2010). In general, agricultural sustainability can be measured in three comprehensive steps:

1. Defining the components: For each dimension of sustainability, relevant components are listed. For instance, crop productivity (component) is associated with economic sustainability (Rasul and Thapa 2003). The use of pesticides, herbicides, and fungicides is linked to environmental sustainability (Rasul and Thapa 2004), whereas the quality of rural life is related to social sustainability (Van Cauwenbergh et al. 2007; Gafsi and Favreau 2010).

2. Defining the indicators: To measure each component, specific indicators are defined. This is the essence of the indicator-based approaches. The indicators might be directly or indirectly related to the components, depending on the nature of the components to be measured and the specifications of researchers. For instance, yield is a direct indicator of crop productivity and the level of prosperity is an indirect indicator of the quality of life.

3. Defining the threshold lines of sustainability: One of the basic ideas behind sustainability measurement is to find out whether a system is sustainable. This has two possible approaches. One compares two systems (e.g., Rasul and Thapa 2004; Meul et al. 2012; Patil et al. 2014), and the other one uses scores and threshold scores (Gafsi and Favreau 2010). The second approach seems more consistent since the first one might compare two systems that are not sustainable. In addition, the use of a scoring system facilitates further aggregation between indicators on the one hand and between components on the other hand.

3.2 Specific method applied: the Participatory Indicator-Based (PIB) approach

Following the general method described above, we applied an indicator-based approach. As a major limitation in previous measurement methods, the choices of indicators are most of the time made by researchers alone and are rarely explained (Meul et al. 2012). In recent years, the participation of stakeholders in designing research has increasingly been acknowledged by several studies, including the ones aiming to integrate multiple dimensions and different views of sustainability (e.g., Binder et al. 2010; Ramos and Caeiro 2010; Lebacq et al. 2013). Although some SIA methods (e.g., König et al. 2012; Rametsteiner et al. 2011; Purushothaman et al. 2012) have already accounted, to some extent, for stakeholders' views in defining the impacts of specific initiatives on sustainability, direct indicators for measuring sustainability are until now based on researchers' choices. Therefore, in contrast to previous DSM methods, we used a PIB approach.

In so doing, a fundamental difference from previous studies is that the output of the current method accounts for both farmers' and agricultural extension officers' viewpoints. In practice, stakeholders had to not only propose some insights in terms of their understanding of and expectations from sustainable agriculture, but also to propose directly measurable indicators and to argue their positions or views. The role of researchers is mainly to coordinate the debate in order to reach a consensus. Accordingly, the participatory approach gives voice to farmers as well as agricultural extension officers through group discussions. Elaborating on the previous general assessment method described above, the specific assessment approach consisted of a four-step process:

1. Organizing group discussions with farmers and agricultural extension officers to identify the required data to measure agricultural sustainability after:

- Determining the list of components associated with each dimension of sustainability and the related indicators,

- Setting up a scoring system and threshold values for each indicator 
2. Designing a household survey questionnaire that will be used to collect the required data;

3. Organizing a household survey for collecting the required primary data as imposed determined by the selected indicators; and

4. Estimating the values of each indicator, component, and dimension of sustainability.

\subsubsection{Group discussions}

Components and indicators Following the general guidelines provided by Ritchie and Lewis (2012), group discussions mainly involved farmers and agricultural extension officers. Beyond the composition of the group, the moderation techniques and the communication processes are quite crucial for the results and the participatory approach used. The participatory approach is a broad concept that refers to a whole process involving at least four levels: (1) participation in decision making in identifying problems, formulating alternative planning activities, allocating resources, etc., (2) participation in implementation in carrying out activities and managing and operating programs (3) participation in economic, social, political, or other benefits individually or collectively (e.g., extension training), and (4) participation in evaluation of the activity and its outcomes for feedback purposes (Uphoff quoted in Khan 1993). Nevertheless, in the context on this study, participation refers only to the involvement of farmers and agricultural extension officers in the definition of sustainability components, indicators, and thresholds through group discussions.

The group discussions were about the concept of sustainability, its dimensions, and the most relevant components and indicators (including the threshold level of sustainability) that might be associated with it. Both men and women were involved in the focus group discussions. Each focus group was composed of seven to eight people, involving farmer leaders (five to six) and agricultural extension officers (two). The composition of each focus group took into account criteria such as gender and experience in agriculture. In total, four focus group discussions were organized in each of the four agroecological zones in northern Benin. Throughout the group work, 12 components and 17 indicators were identified to measure agricultural sustainability at the farm level (Table 1).

Scoring system and threshold of sustainability One of the requirements for processing multiple indicators within an aggregation framework is that all are reduced to the same scale, with common units (Nardo et al. 2005). Thus, all indicators must be normalized, preferably to a continuous numerical scale, in order to allow mathematical procedures such as linear-additive aggregation to be performed (Paracchini et al. 2011).
In order to facilitate interpretations and combinations between indicators within the components, we defined a uniform 5-level scoring scale (from 1 to 5) for each indicator (Table 2). In terms of sustainability or contribution to overall agricultural sustainability, 1, 2, 3, 4, and 5 mean very low, low, medium, high, and very high sustainability, respectively. Before defining the real values behind each level of the scale, threshold values of sustainability were fixed and given level 3 . Then, the remaining levels $(1,2,4$, and 5) were set up around the threshold value of the indicator. By using such a scoring approach, some indicators might be more important or dominant than others in the sense that a bad (low) value of one component associated with a good level of sustainability overrides better (higher) values in other components also associated with a good level of sustainability. To avoid this bias, we associated only a high value (score) with a good level of sustainability. For instance, higher technical efficiency and lower doses of pesticides both refer to a high score of economic and environmental sustainability, respectively.

For each indicator, a threshold of sustainability is an interval of values corresponding to a level of sustainability. The threshold values were defined from focus group discussions with farmers and agricultural extension officers cross-checked with secondary literature. The threshold values did not vary significantly among the focus groups. As an expectation, if a farming system is sustainable, its current or measured level of sustainability should be on the threshold (i.e., level 3) or above it. For the available capital indicator, a theoretical budget for a farm of 1 ha of maize was designed in a focus group. Then, around the theoretical budget (about 100,000 francs CFA/ha), we set the sustainability thresholds. For net income, calculation of the threshold value was based on the SMIG (InterProfessional Minimum Wage or Salary), which is about 30,000 francs CFA/month, giving about 360,000 francs CFA/year based on the assumption that, from farm income, farmers should be able to obtain as much money as they could obtain if they were workers. Finally, the thresholds of indicator doses of fertilizers and herbicides were based on the doses recommended by the National Institute of Agricultural Research in Benin (INRAB). The threshold values of the remaining indicators were derived from farmers' experience. In practice, stakeholders were asked to define intervals of these indicators that a sustainable farming system would have considering the different levels of sustainability scored as 1, 2, 3, 4 , and 5 .

\subsubsection{Household survey questionnaire}

From the results of the group discussions, the data required to measure each indicator of sustainability were identified (Table 1). Based on these required data, a questionnaire was designed for data collection through a household survey. In 


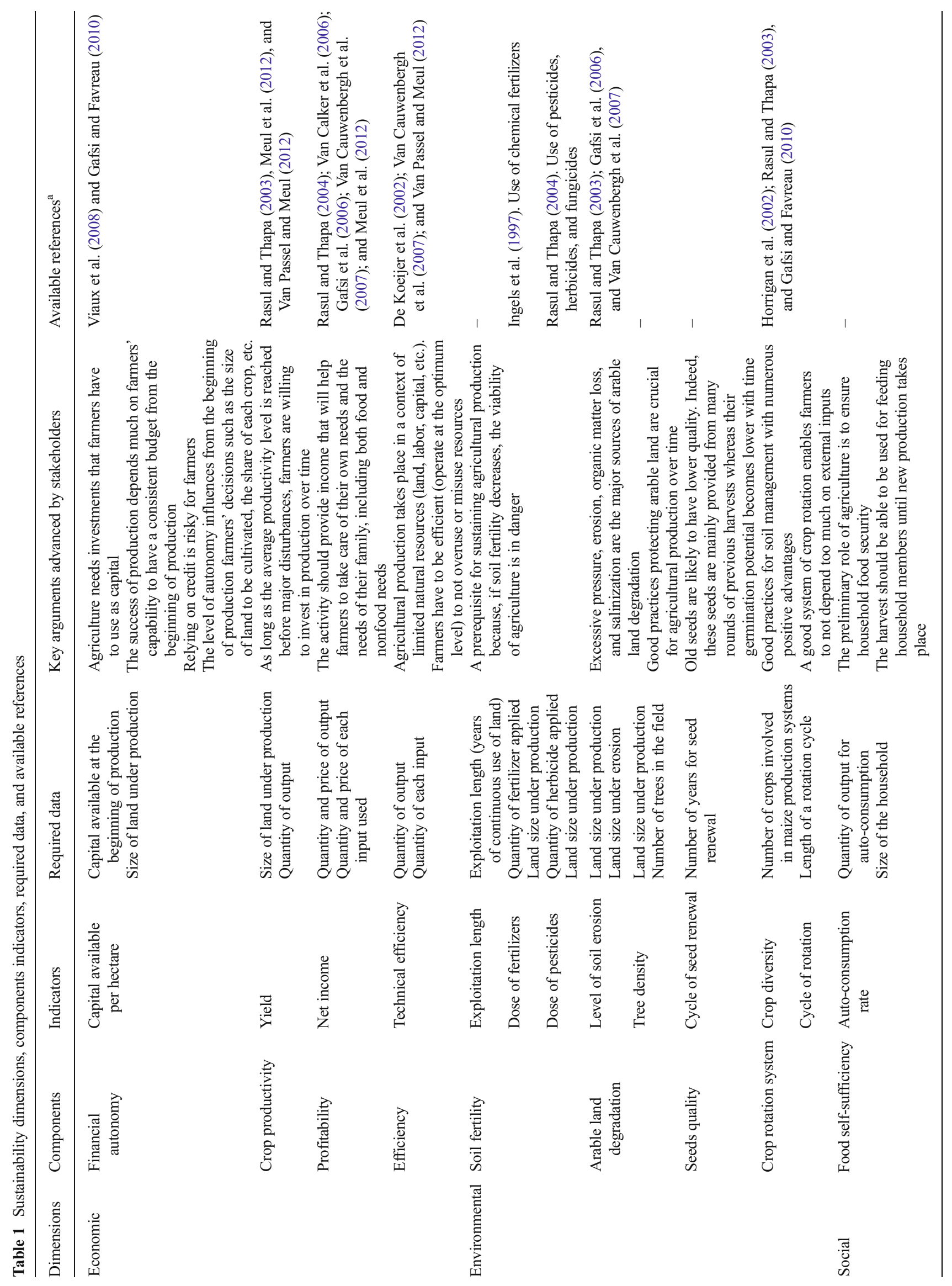




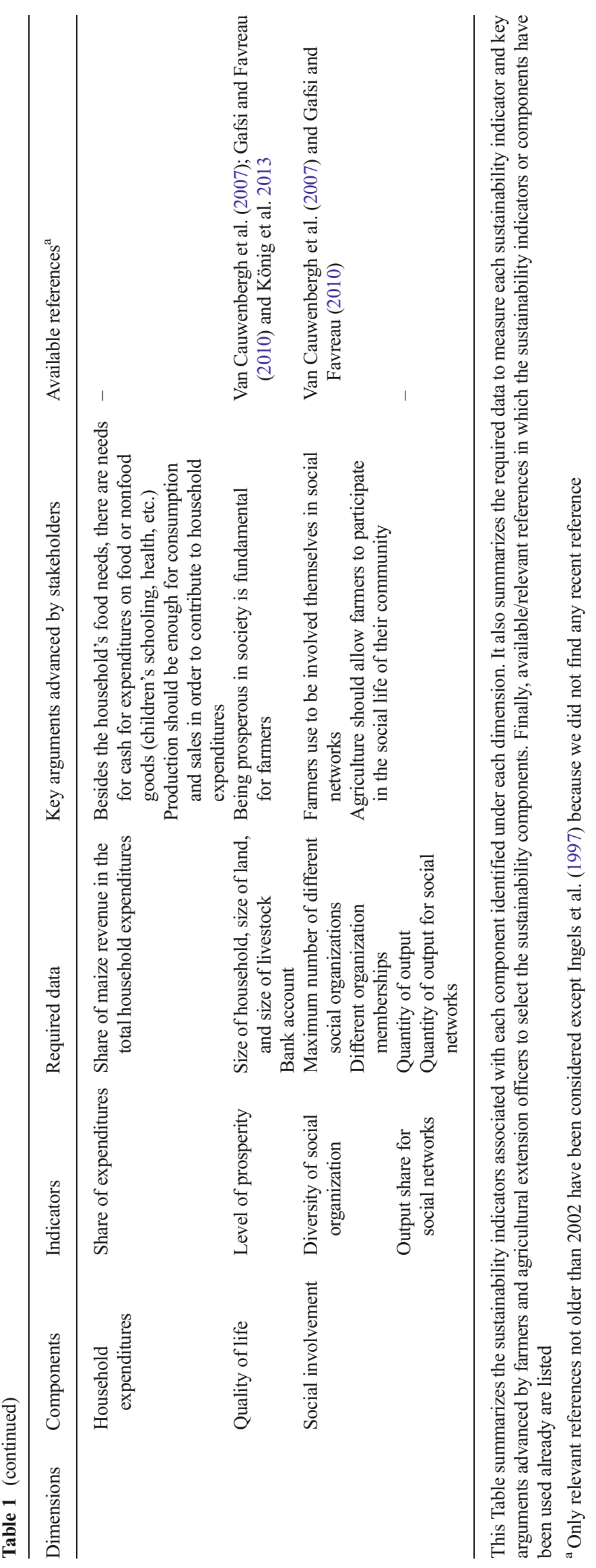

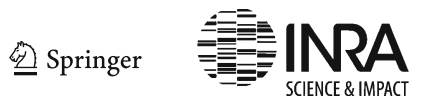


Table 2 Scoring scales of sustainability indicators of maize production in northern Benin

\begin{tabular}{|c|c|c|c|c|c|}
\hline $\begin{array}{l}\text { Scores } \\
\text { Indicators (dimensions) }\end{array}$ & $\begin{array}{l}\text { Very low } \\
\text { (1) }\end{array}$ & $\begin{array}{l}\text { Low } \\
\text { (2) }\end{array}$ & $\begin{array}{l}\text { Average } \\
\text { (3) }\end{array}$ & $\begin{array}{l}\text { High } \\
\text { (4) }\end{array}$ & $\begin{array}{l}\text { Very high } \\
\text { (5) }\end{array}$ \\
\hline Capital available (francs CFA/ha) & $<20,000$ & $20,000-80,000$ & $80,000-150,000$ & $150,000-300,000$ & $>300,000$ \\
\hline Yield (kg/ha) & $<1,000$ & $1,000-2,000$ & $2,000-3,000$ & $3,000-4,000$ & $>4,000$ \\
\hline Net income (francs CFA) & $<100,000$ & $100,000-300,000$ & $300,000-400,000$ & $400,000-600,000$ & $>600,000$ \\
\hline Technical efficiency (\%) & $<10$ & $10-30$ & 30-50 & $50-70$ & $>70$ \\
\hline Exploitation length (years) & $>16$ & $12-16$ & 8-12 & $4-8$ & $<4$ \\
\hline Dose of fertilizer (kg/ha) & $>400$ & $300-400$ & $200-300$ & $100-200$ & $<100$ \\
\hline Dose of pesticide (L/ha) & $>5$ & $4-5$ & $3-4$ & $2-3$ & $<2$ \\
\hline Level of soil erosion (\%) & $>20$ & $15-20$ & $10-15$ & $5-10$ & $<05$ \\
\hline Tree density (trees/ha) & $<4$ & $4-8$ & $8-12$ & $12-16$ & $>16$ \\
\hline Cycle of seed renewal (years) & $>4$ & $3-4$ & 2-3 & $1-2$ & $<1$ \\
\hline Crop diversity (crops) & $<2$ & $2-3$ & $3-4$ & $4-5$ & $>5$ \\
\hline Cycle of rotation (years) & $<1$ & $1-2$ & 2-3 & $3-4$ & $>4$ \\
\hline Auto-consumption rate (kg/household member) & $<200$ & $200-400$ & $400-600$ & $600-800$ & $>800$ \\
\hline Share of expenditures (\%) & $<10$ & $10-30$ & 30-50 & $50-70$ & $>70$ \\
\hline Level of prosperity (classes) & 1 & 2 & 3 & 4 & 5 \\
\hline Diversity of social organizations (\%) & $<10$ & $10-20$ & 20-30 & $30-40$ & $>40$ \\
\hline Output share for social networks (\%) & $<5$ & $5-10$ & 10-15 & $15-20$ & $>20$ \\
\hline
\end{tabular}

This Table presents the scoring scales applied to each sustainability indicator. The average score (score 3 ) is the sustainability threshold. These scoring scales were used to match the measured values of each sustainability indicator to scores $1,2,3,4$, or 5 . Francs CFA $650 \approx$ Euro 1

addition to the required data, farmers' socioeconomic conditions can be determined for further modeling purposes.

\subsubsection{Household survey}

The aim is to collect all data required to measure the sustainability indicators. The household survey was conducted through individual interviews with a sample of respondents. Afterward, the collected data were coded and entered into Excel for further processing.

\subsubsection{Estimation of the values of indicators, components, and dimensions}

The value of each indicator was equal to its sustainability score $(1,2,3,4$, or 5$)$. To simplify the calculations, an equal weighting method was used under each dimension and component of sustainability, implying a simple and linear aggregation technique. Thus, the value of a given component is equal to the average score of its related indicators. Considering a component $C$ with $i$ indicators $(I)$, its value $\left(V_{C}\right)$ is given as:

$V_{C}=N^{-1} \cdot \sum_{i} V_{I i}$

where $N$ is the number of indicators related to the component $C$ and $V_{I i}$ is the value (score) of the $i^{\text {th }}$ indicator. Therefore, the maximum value of each component was 5 and the minimum 1 .
The value of each dimension is the sum of values of its components. Moreover, we set the maximum value of each dimension at 100 . In so doing, the maximum value of each dimension was 100 and the minimum 20 . The value $\left(V_{D}\right)$ of a given dimension $D$ with $j$ components is given by:

$V_{D}=20 . j^{-1} \cdot \sum_{j} V_{C j}$

\subsection{Study zone}

The study took place in northern Benin, located between $8^{\circ}$ $30^{\prime}$ and $12^{\circ} 20^{\prime}$ North and $1^{\circ} 00^{\prime}$ and $3^{\circ} 90^{\prime}$ East. This region, considered the food basket of Benin, is divided into four agroecological zones. Both focus group discussions and a household survey were conducted in the same area.

To facilitate an illustration of the method, we focused only on maize production. However, the method is relevant and applicable to other types of farms. With support from agricultural extension officers of Centre Communal de Promotion Agricole (CeCPA), a total of 336 maize producers were sampled randomly in eight villages selected in the four agroecological zones according to farming system diversity and the importance of maize farming. The household survey was conducted through individual interviews based on the survey questionnaire. Data were analyzed by using descriptive statistics in Excel and sensitivity $t$ tests in STATA 11. The 
respondents were mainly men about 40 years old and heads of households with 13 members on average. Agriculture is the main activity of $94.35 \%$ of the respondents, and the average farm size in terms of land under use is $11.61 \mathrm{ha}$, including fallows and land not in use. Table 3 summarizes the descriptive statistics of the data required by the framework.

\section{Results and discussion}

\subsection{Current level of agricultural sustainability}

Figure 2 presents the current levels of economic, environmental, and social sustainability of maize farming in northern Benin. This figure reveals that, in the current state and on average, maize farming presented weaknesses in the economic and social spheres but showed positive scores in the environmental area. Following the definition of sustainability, maize farming in northern Benin is vulnerable to disturbances such as land degradation and climate change that adversely affect agriculture. This result is quite illustrative of the constraints to the agricultural sustainability of maize farming in northern Benin. Such a picture can therefore serve as a tool for decision-makers as specific and relevant policy recommendations could be easily derived from it.

\subsubsection{Economic sustainability}

The components of economic sustainability were all under the threshold values except for the profitability component, which is under the threshold but very close to it (Fig. 2). It turns out that farmers did not have strong financial autonomy (sustainability score 2.09). In addition, the productivity level was still low (sustainability score 1.85), and the combination of inputs not technically efficient (sustainability score 2.07). Nevertheless, maize production could provide a positive net income to farmers (sustainability score 2.82), almost equal to the minimum wage in Benin. Given that picture, the average value of economic sustainability of maize farming was 41.44 . This current level of economic sustainability is statistically below the threshold line of sustainability (value 50). Indeed, the $t$ test of one sample mean comparison revealed a highly significant difference, at the $1 \%$ level $(P<0.01)$, between the current level of economic sustainability and the expected threshold.

Table 3 Descriptive statistics of sustainability indicators of maize production in northern Benin

\begin{tabular}{|c|c|c|}
\hline Indicators (dimensions) & Mean values measured & Mean scores \\
\hline Capital available (francs CFA/ha) & $58,056.51(26,666.66)$ & $2.09(0.81)$ \\
\hline Yield (kg/ha) & $1,265.80(748.81)$ & $1.85(0.82)$ \\
\hline Net income (francs CFA) ${ }^{\mathrm{a}}$ & $701,278.6(840,778.30)$ & $2.82(1.68)$ \\
\hline Technical efficiency $^{\mathrm{b}}$ & $0.58(0.19)$ & $2.07(0.97)$ \\
\hline Exploitation length (years) & $11.23(6.02)$ & $2.82(1.15)$ \\
\hline Dose of fertilizer $(\mathrm{kg} / \mathrm{ha})$ & $167.19(81.48)$ & $3.81(0.80)$ \\
\hline Dose of pesticide (L/ha) & $2.73(1.91)$ & $3.95(1.08)$ \\
\hline Level of soil erosion $(\%)$ & $19.93(21.64)$ & $3.36(1.68)$ \\
\hline Tree density (trees/ha) & $12.36(9.10)$ & $3.11(1.33)$ \\
\hline Cycle of seed renewal (years) & $2.51(1.40)$ & $2.09(1.20)$ \\
\hline Crop diversity (crops) & $2.31(0.57)$ & $1.78(0.70)$ \\
\hline Cycle of rotation (years) & $2.54(0.92)$ & $2.36(1.15)$ \\
\hline Auto-consumption rate (kg/household member) & $134.20(168.17)$ & $1.29(0.70)$ \\
\hline Share of expenditures (\%) & $41.38(34.82)$ & $2.90(1.51)$ \\
\hline Level of prosperity (classes) $^{c}$ & $1.87(1.07)$ & $1.87(1.07)$ \\
\hline Diversity of social organizations (\%) & $20.56(10.03)$ & $1.95(0.97)$ \\
\hline Output share for social networks (\%) & $10.89(10.79)$ & $1.95(1.19)$ \\
\hline
\end{tabular}

This Table presents the descriptive statistics of sustainability indicators and the corresponding sustainability scores. Following the scoring scales, each indication is expected to have a minimum value of 1 and a maximum value of 5. Indicators with scores above the average sustainability threshold (score 3) highlight high or very high sustainability, whereas indicators with scores below the average sustainability threshold indicate low or very low sustainability. Francs CFA $650 \approx$ Euro 1 ; values in parentheses are standard deviations

${ }^{\mathrm{a}}$ Net income: gross product - total costs of production (variable and fixed costs)

${ }^{\mathrm{b}}$ Estimation method: stochastic frontier analysis (SFA) using a Cobb-Douglas model

${ }^{\mathrm{c}}$ Cluster analysis with variables: size of household, farm size, possession of livestock, and bank account 


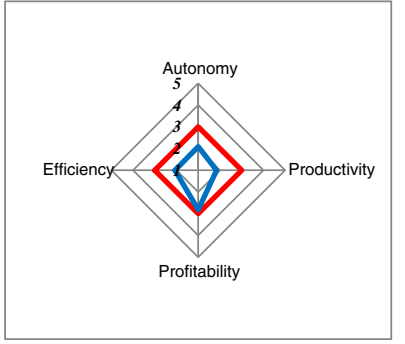

Levels of economic sustainability components

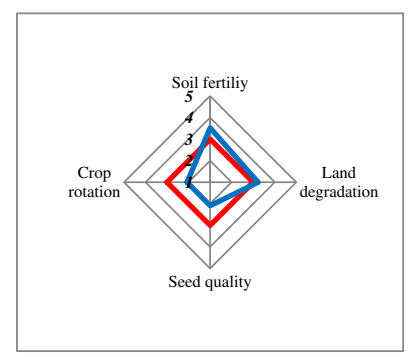

Levels of environmental sustainability components

Fig. 2 Current levels of economic, environmental, and social sustainability of maize farming in northern Benin. Eco. Economic, Env. Environmental, Soc. Social. The red and blue lines are the average threshold of

\subsubsection{Environmental sustainability}

Maize farming in northern Benin was sustainable with respect to soil fertility (sustainability score 3.52) and land degradation level (sustainability score 3.23 ). The two components were the main sources of the good environmental value in overall sustainability (Fig. 2). Seed quality (sustainability score 2.09) and the crop rotation system (sustainability score 2.07) were still components to be improved. On average, the value of environmental sustainability of maize farming was 54.66. This current level of environmental sustainability was statistically above the threshold line (value 50). Moreover, the $t$ test of one sample mean comparison revealed a highly significant difference, at the $1 \%$ level $(P<0.01)$, between the current level of environmental sustainability and the expected threshold.

\subsubsection{Social sustainability}

Food security (sustainability score 1.29), social involvement (sustainability score 1.96), and quality of life (sustainability score 1.87) were the three components that constrained social sustainability (Fig. 2). The level of the component share of expenditures (sustainability score 2.9) was close to the threshold line. On average, the value of social sustainability of maize farming was 39.80. This current level of social sustainability is statistically below the threshold line (value 50). The $t$ test of one sample mean comparison revealed a highly significant difference, at the $1 \%$ level $(P<0.01)$, between the current level of social sustainability and the expected threshold.

\subsection{Strengths and weaknesses of the PIB approach}

Stakeholder participation in the development of indicators is not only crucial for selecting regionally relevant indicators but also for improving the recognition and use of indicator results (Rametsteiner et al. 2011). Moreover, as suggested by Hayati et al. (2010), indicators used for agricultural sustainability should be location specific. These prerequisites are fulfilled

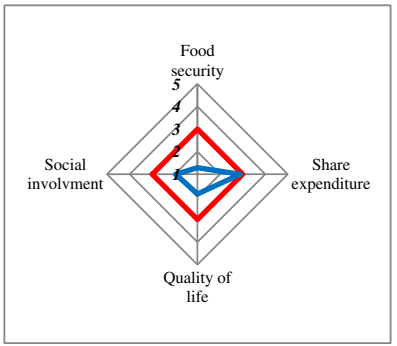

Levels of the components of social sustainability

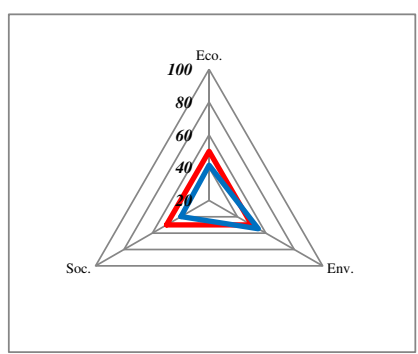

Levels of the dimensions of the agricultural sustainability of maize farming sustainability and the current level of sustainability, respectively. If maize farming is sustainable, the blue line is expected to be on the red line or above it. Otherwise, maize farming in northern Benin is not sustainable

by the PIB approach. It is the first attempt to measure agricultural sustainability by using a direct measurement method based on participatory indicators in the context of a developing country in sub-Saharan Africa.

First, the entire method is based on a participatory approach, allowing researchers to value local knowledge when measuring agricultural sustainability. To some extent, besides the shortcomings of participatory approaches in which the results largely depend on moderation techniques, the method could be criticized for being a mix of participatory and expertdriven approaches since researchers are involved, more or less actively, in some stages. Nevertheless, the PIB approach emphasizes building up a framework on farmers' and agricultural extension officers' viewpoints in terms of agricultural sustainability. Subsequently, the application of a PIB approach for measuring agricultural sustainability requires that researchers be fully aware of participatory tools.

Given that previous assessment methods used the collection of specific data selected only by researchers, the proposed approach could require more time for implementation. Indeed, any further studies aiming at measuring sustainability and willing to apply the proposed PIB approach should at least start from step 2 (Setting up a scoring system and thresholds). However, we strongly recommend up-dating or checking/ validating the relevance of the indicators through focus group discussions. In both cases, updating the threshold values in group discussions (including the values behind the scoring scale) is a fundamental prerequisite for applying this approach. This makes the methods adaptable in terms of both time and space. This makes more sense because the sustainability level (threshold) of a given indicator might be different across regions and might also change over time.

As a shortcoming, the framework measures relative sustainability and is definitely likely to be location specific. This would not allow a comparison of the final outcome between two countries with different socioeconomic conditions or even within the same country. But, this limitation could also be a strength since it makes the framework rather flexible and location specific. As a matter of fact, two countries or two 
different regions within the same country are very likely to have different socioeconomic features. Another shortcoming could be that the PIB approach as presented in this paper is not suitable for assessing the temporal and spatial dimensions of agricultural sustainability. Regardless of the participatory approach, there is a good debate about indicator-based approaches in the literature as one of the major weaknesses of these approaches is that they fail to highlight the temporal and spatial dimensions of sustainability. Finally, the indicators and even the threshold of sustainability yielded with the PIB approach are very likely to be as subjective as the sustainability concept itself.

4.3 Is the PIB approach outcome related to previous methods?

Most of the sustainability indicators used corroborate with a good number of empirical research efforts applying SIA or DSM methods (Table 1). Indeed, although the current study partly used an innovative approach - the PIB approach, for instance - for designing the framework of sustainability measurement, some suggested components or indicators found are also proposed in the abundant literature on agricultural sustainability assessment. The new indicators are found under the environmental dimension (i.e., length of continuous land exploitation, tree density, and seed quality) and social dimension (i.e., food security, share of expenditures, and output share for social networks) of sustainability. It is often observed that farmers reduce the length of fallow or do not practice it anymore. This situation poses, ceteris paribus, the difficulty of soil regeneration. Tree density contributes to the control of soil erosion and therefore maintains the system before major disturbances. Also, in the study zone, having trees in the field and being able to decide on whether to cut them or plant new ones refers to land ownership (Yegbemey et al. 2013). Seed quality is also a new indicator that accounts for environmental sustainability. Good seed quality helps to sustain crop yield and decreases pathogen and pest attacks and sprays, therefore reducing the use of plant protection products.

The new indicators of social sustainability reflect more of the specificities of developing countries. Food security is well known as a major challenge in developing countries and therefore it is worthy of being a component of sustainability. Likewise, agriculture is expected to provide cash to meet other food or nonfood needs. Thus, the household's share of expenditures for an activity comes up as an expectation from a sustainable system. Beyond the social involvement commonly used, farmers also emphasized the output share for social networks. Indeed, one should not only belong to social organizations, but also take part in the processes of gifting and sharing that are very developed in developing countries, especially in Africa. These new indicators might be full of information for agricultural policymakers. Indeed, they give direct feedback on the expectations of farmers in terms of agricultural sustainability.

\subsection{Measured level of sustainability}

The low financial autonomy could be linked to low income and the context of poverty in rural areas in developing countries in general, and in Benin particularly. Agriculture generates on average and per year low income of francs CFA 222,932.59 for maize in Nigeria (Oladejo and Adetunji 2012) and Francs CFA 21,700 for cotton in northeastern Benin (Paraïso et al. 2012). According to Jayne et al. (2003), mean annual per capita household income varied from $\$ 43$ (francs CFA 21,554.4) in Mozambique to $\$ 337$ (about francs CFA 168,926) in Kenya. In addition, in most of the countries in Africa, poverty is well known to be predominant in rural areas (Dercon 2009). The productivity of maize farming (average yield of $1,265.80 \mathrm{~kg} / \mathrm{ha}$ ) is still low while it is well established that even local varieties in Benin can yield up to $1,500 \mathrm{~kg} / \mathrm{ha}$. Somehow, farmers underuse or overuse inputs, implying low technical efficiency, which does not necessarily affect productivity or income. The good result for environmental sustainability is mainly because farmers, on average, use doses of pesticides below or equal to the recommended doses. Nevertheless, the duration of seed renewal and the crop rotation system as they are do not favor good sustainability of the system. Considering the social dimensions of sustainability, the low level of food security may also be considered sustainable since farmers might have a wide range of food patterns even if maize is a staple food. The share of expenditures shows the social role of maize production. According to Yabi and Moustafa (2011), maize is becoming a cash crop, able to generate consistent income. The low quality of life is linked with poverty. The low social involvement could be explained by the fact that farmers' associations in agriculture mainly focus on cotton.

\section{Conclusions}

This is the first attempt to measure agricultural sustainability by using direct measurement methods based on a PIB approach in the context of a developing country in sub-Saharan Africa. To some extent, many sustainability indicators proposed by farmers and agricultural extension officers corroborate with those already mentioned in the literature. Some new indicators emerged in the spheres of environmental and social sustainability. The main strengths of this approach are its participatory nature and its flexibility (location-specific indicators). However, the approach also has a major weakness related to the subjectivity of components, indicators, and thresholds of sustainability.

An illustration of the application of the framework with a focus on maize farming in Benin, West Africa, revealed that 
maize farming in northern Benin shows low economic and social sustainability. This early-warning information suggests that better extension support aiming at enhancing farmers' technical efficiency could help move the level of economic sustainability close to or above the threshold of sustainability. In addition, research and agricultural extension services should work to provide farmers with good seeds and promote practices such as seed renewal while the current amounts of fertilizer and pesticide use should be kept as they are because substantial increases will decrease the current level of environmental sustainability. Finally, promoting specific associations such as development associations could improve farmers' involvement in social life. Future research could improve the aggregation technique by using non-linear schemes in which the weights of sustainability components and indicators are defined by stakeholders.

Acknowledgments The authors are grateful to the International Foundation for Science (IFS), Stockholm, Sweden, and the German Academic Exchange Service (DAAD) for financing this research. Our thanks also go to Ghislain Aihouton and Michel Atchikpa for helping in data collection, and the three outstanding reviewers for their comments and suggestions.

\section{References}

Binder CR, Feola G, Steinberger JK (2010) Considering the normative, systemic and procedural dimensions in indicator-based sustainability assessments in agriculture. Environ Impact Assess Rev 30:7181. doi:10.1016/j.eiar.2009.06.002

Conway GR (1985) Agroecosystem analysis. Agric Admin 20:31-55

De Koeijer TJ, Wossink GAA, Struik PC, Renkema JA (2002) Measuring agricultural sustainability in terms of efficiency: the case of Dutch sugar beet growers. J Environ Manage 66(1):9-17. doi:10.1006/ jema.2002.0578

Dercon S (2009) Rural poverty: old challenges in new contexts. World Bank Res Obs (2009) 24(1):1-28

Fleming A, Vanclay F (2010) Farmer responses to climate change and sustainable agriculture: a review. Agron Sustain Dev 30:11-19. doi: 10.1051/agro/2009028

Gafsi M, Favreau JL (2010) Appropriate method to assess the sustainability of organic farming systems. Proceeding of the 9th European IFSA Symposium, 4-7 July 2010, Vienna (Austria): http://ifsa.boku. ac.at/cms/fileadmin/Proceeding2010/2010 WS2.1 Gafsi.pdf

Gafsi M, Legagneux B, Nguyen G, Robin P (2006) Towards sustainable farming systems: effectiveness and deficiency of the French procedure of sustainable agriculture. Agric Syst 90:226-242

Hayati D, Ranjbar Z, Karami E (2010) Measuring agricultural sustainability. In Lichtfouse E. (ed.), Biodiversity, Biofuels, Agroforestry and Conservation Agriculture. Sustainable Agriculture Reviews 5. 10.1007/978-90-481-9513-8_2

Heller MC, Keoleian GA (2003) Assessing the sustainability of the US food system: a life cycle perspective. Agric Syst 76:1007-1041

Horrigan L, Robert SL, Walker P (2002) How sustainable agriculture can address the environment and human health harms of industrial agriculture. Environ Health Perspect 110(5):445-456

Ingels C, Campbell D, George MR, Bradford E (1997) What is sustainable agriculture? UC Sustainable Agriculture Research and
Education Program. Available online: www.sarep.ucdavis.edu/ concept.htm. Last accessed: 12 Oct 2010

Jayne TS, Yamano T, Weber MT, Tschirley D, Benfica R, Chapoto A, Zulu B (2003) Smallholder income and land distribution in Africa: implications for poverty reduction strategies. Food Policy 28:253275. doi:10.1016/S0306-9192(03)00046-0

Khan NA (1993) Towards an understanding of 'participation'; the conceptual labyrinth revisited. Admin Change XX(1-2):106120

König HJ (2013) Operationalising sustainability impact assessment of land use scenarios in developing countries: a stakeholder-based approach with case studies in China, India, Indonesia, Kenya, and Tunisia. PhD Thesis, Mathematisch-Naturwissenschaftlichen Fakultät, Universität Potsdam.

König HJ, Sghaier M, Schuler J, Abdeladhim M, Helming K, Tonneau JP, Ounalli N, Imbernon J, Morris J, Wiggering H (2012) Participatory impact assessment of soil and water conservation scenarios in Oum Zessar Watershed, Tunisia. Environ Manage 50:153-165. doi:10. 1007/s00267-012-9865-y

Lebacq T, Baret PV, Stilmant D (2013) Sustainability indicators for livestock farming: a review. Agron Sustain Dev 33:311-327. doi: 10.1007/s13593-012-0121-x

Liu F, Zhang H (2013) Novel methods to assess environmental, economic, and social sustainability of main agricultural regions in China. Agron Sustain Dev 33:621-633. doi:10.1007/s13593-012-0131-8

Lynam JK, Herdt RW (1989) Sense and sustainability: sustainability as an objective in international agricultural research. Agric Econ 3:381398. doi:10.1016/0169-5150 (89)90010-8

Meul M, Van Passel S, Fremaut D, Haesaert G (2012) Higher sustainability performance of intensive grazing versus zero-grazing dairy systems. Agron Sustain Dev 32:629-638. doi:10.1007/s13593-0110074-5

Nardo M, Saisana M, Saltelli A, Tarantola S, Hoffman A, Giovannini E (2005) Handbook on constructing composite indicators: methodology and user guide. OECD Statistics Working Paper, Paris

Ness B, Urbel-Piirsalu E, Anderberg S, Olsson L (2007) Categorising tools for sustainability assessment. Ecol Econ 60:498-508. doi:10. 1016/j.ecolecon.2006.07.023

Oladejo JA, Adetunji MO (2012) Economic analysis of maize (Zea mays L.) production in Oyo state of Nigeria. Agric Sci Res 2(2):77-83

Paracchini ML, Pacini C, Jones MLM, Perez-Soba M (2011) An aggregation framework to link indicators associated with multifunctional land use to the stakeholder evaluation of policy options. Ecol Indic 11:71-80. doi:10.1016/j.ecolind.2009.04.006

Paraïso A, Yabi AJ, Sossou A, Zoumarou-Wallis N, Yegbemey RN (2012) Rentabilité économique et financière de la production cotonnière à ouaké au nord-ouest du Bénin. Ann Sci Agron 16(1): 91-105

Patil S, Reidsma P, Shah P, Purushothaman S, Wolf J (2014) Comparing conventional and organic agriculture in Karnataka, India: where and when can organic farming be sustainable? Land Use Policy 37:40 51. doi:10.1016/j.landusepol.2012.01.006

Pope J, Annandale D, Morrison-Saunders A (2004) Conceptualising sustainability assessment. Environ Impact Assess Rev 24:595616. doi:10.1016/j.eiar

Purushothaman S, Patil S, Francis I, König HJ, Reidsma P, Hegde S (2012) Participatory impact assessment of agricultural practices using the land use functions framework: a case study from India. Int J Biodiversity Sci Ecosyst Serv Manage 9(10):2-12. doi:10. 1080/21513732.2012.721005

Rametsteiner E, Pulzl H, Alkan-Olsson J, Frederiksen P (2011) Sustainability indicator development: science or political negotiation? Ecol Indic 11:61-70. doi:10.1016/j.ecolind.2009.06.009

Ramos TB, Caeiro S (2010) Meta-performance evaluation of sustainability indicators. Ecol Indic 10:157-166. doi:10.1016/j.ecolind.2009. 04.008 
Rasul G, Thapa GB (2003) Sustainability analysis of ecological and conventional agricultural systems in Bangladesh. World Dev 31(10):1721-1741. doi:10.1016/S0305-750X(03)00137-2

Rasul G, Thapa GB (2004) Sustainability of ecological and conventional agricultural systems in Bangladesh: an assessment based on environmental, economic and social perspectives. Agric Syst 79:327351. doi:10.1016/S0308-521X(03)00090-8

Reidsma P, König H, Feng S, Bezlepkina I, Nesheim I, Bonin M, Sghaier M, Purushothaman S, Sieber S, Van Ittersum MK, Brouwer F (2011) Methods and tools for integrated assessment of land use policies on sustainable development in developing countries. Land Use Policy 28:604-617. doi:10.1016/j.landusepol.2010.11.009

Rigby D, Woodhouse P, Young T, Burton M (2001) Constructing a farm level indicator of sustainable agriculture practice. Ecol Econ 39: 463-478. doi:10.1016/S0921-8009 (01)00245-2

Ritchie J, Lewis J (Eds.) (2012) Qualitative research practice: a guide for social science students and researchers. Sage Publications Limited. First published in 2003. ISBN: 978-0-7619-7109-2c

Sydorovych O, Wossink A (2008) The meaning of agricultural sustainability: evidence from a conjoint choice survey. Agric Syst 98:10 20. doi:10.1016/j.agsy.2008.03.001

Van Calker KJ, Berentsen PBM, Romero C, Giesen GWJ, Huirne R (2006) Development and application of multi-attribute sustainability function for Dutch dairy farming systems. Ecol Econ 57:640-658. doi:10.1016/j.ecolecon.2005.05.016

Van Cauwenbergh N, Biala K, Bielders C, Brouckaert V, Franchois L, Cidad VG, Hermy M, Mathijs E, Muys B, Reijnders J, Sauvenier X,
Valckx J, Vanclooster M, der Veken BV, Wauters E, Peeters A (2007) SAFE - a hierarchical framework for assessing the sustainability of agricultural systems. Agric Ecosyst Environ 120:229-242. doi:10.1016/j.agee.2006.09.006

Van der Werf HMG, Petit J (2002) Evaluation of the environmental impact of agriculture at the farm level: a comparison and analysis of 12 indicator-based methods. Agric Ecosyst Environ 93(1-3): 131-145. doi:10.1016/S0167-8809(01)00354-1

Van Passel S, Meul M (2012) Multilevel and multi-user sustainability assessment of farming systems. Environ Impact Assess Rev 32:170 180. doi:10.1016/j.eiar.2011.08.005

Van Passel S, Nevens F, Mathijs E, Huylenbroeck GV (2007) Measuring farm sustainability and explaining differences in sustainable efficiency. Ecol Econ 62(1):149-161. doi:10.1016/j.ecolecon.2006.06.008

Viaux F, Zahm P, Vilain L, Girardin P, Mouchet C (2008) Farm sustainability assessment using the IDEA method: from the concept of farm sustainability to case studies on French farms. Sustain Dev 16(4): 271-281. doi:10.1002/sd.380

Yabi JA, Moustafa R (2011) Analysis of maize production and supply for food security improvement in the Borgou region in Northeast of Benin. Bauer S, Budjurova E (eds) International Book "Issues and Challenges in Rural Development”. 4: 222-237. ISBN 978-3-82361620-7.

Yegbemey RN, Yabi JA, Tovignan SD, Gantoli G, Kokoye SHE (2013) Farmers' decisions to adapt to climate change under various property rights: a case study of maize farming in Northern Benin (West Africa). Land Use Policy 34:168-175. doi:10.1016/j.landusepol.2013.03.001 